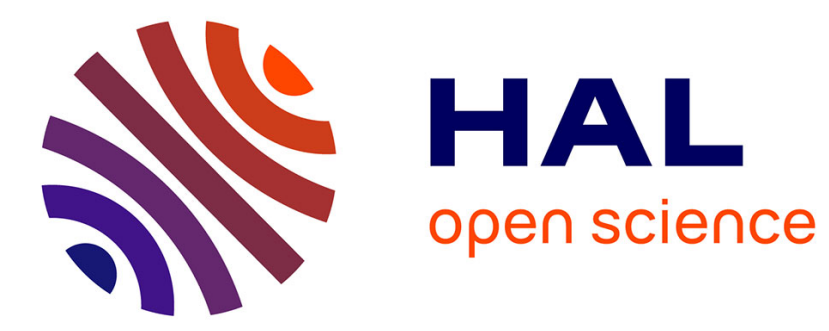

\title{
ACTIVE LEARNING BY VIRTUAL PROTOTYPING TECHNIQUE
}

Mariana Fratu, Jean-Paul Becar, Jean-Charles Canonne, Aurel Fratu

\section{To cite this version:}

Mariana Fratu, Jean-Paul Becar, Jean-Charles Canonne, Aurel Fratu. ACTIVE LEARNING BY VIRTUAL PROTOTYPING TECHNIQUE. ICERI2015 Conference, IATED, Nov 2015, SEVILLE, Spain. hal-02513142

\section{HAL Id: hal-02513142 \\ https://uphf.hal.science/hal-02513142}

Submitted on 23 Mar 2020

HAL is a multi-disciplinary open access archive for the deposit and dissemination of scientific research documents, whether they are published or not. The documents may come from teaching and research institutions in France or abroad, or from public or private research centers.
L'archive ouverte pluridisciplinaire HAL, est destinée au dépôt et à la diffusion de documents scientifiques de niveau recherche, publiés ou non, émanant des établissements d'enseignement et de recherche français ou étrangers, des laboratoires publics ou privés. 


\title{
ACTIVE LEARNING BY VIRTUAL PROTOTYPING TECHNIQUE
}

\author{
Mariana Fratu ${ }^{1}$, Jean-Paul Bécar ${ }^{2}$, Jean-Charles Canonne ${ }^{2}$, Aurel Fratu ${ }^{\text {] }}$ \\ ${ }^{1}$ University of Transylvania in Brasov (ROMANIA) \\ ${ }^{2}$ University of Valenciennes (FRANCE)
}

\begin{abstract}
In this paper, the development of virtual prototypes models and their testing for active learning support is described. The personalized virtual applications selected by a tutor are used directly for performing active learning at the university's separated workplace. When using the virtual prototypes the main strategy of the informatics support is based on the developing informatics tools which are adapted for a pedagogical engineering content. On-line learning outcomes materials, as virtual prototypes, were created and tested on the desktop environment. Some of them were also investigated as the "active elements" for active learning, especially for writing stage rapports including practical projects. The practice showed that the testing of issues such as the practical stage work can result in an active learning process. Virtual prototyping technique, as method for active learning informatics support, requires the further refinement and also the enhancement of students' informatics skills, as well.
\end{abstract}

Keywords: active learning, virtual prototyping, modern strategy for learning.

\section{Introduction}

Active learning can involve individual students in doing things and reflecting on what they have done, or it can involve students working cooperatively in pairs or groups. Active learning instructional strategies can be created and used to engage students in thinking critically or creatively. One of the most obvious ways to increase the students' interest for study is to involve her active participation. This strategy will keep students engaged during the most time and they will retain information with greater ease and with more success. There are many effective ways for students to generate new ideas.

Working with pairs or in small groups tends to be effective because students stimulate each other's thought active teaching process. Encouraging students to think out of the box and to investigate into a topic using the active learning technique often has unexpectedly positive results. When students are actively involved in the learning task, they learn more than when they are passive receivers of instruction. When students are passive, their brain doesn't do an especially effective job of processing or retaining the information. When students take the initiative to work active in the projects their interest and confidence increase. We must ask students to involve themselves in their active learning by using virtual prototyping technique.

\section{Active learning strategies for active students}

Active learning instructional strategies include a wide range of activities that share the common element of involving students in doing things and thinking about the things they are doing. Active learning is a process wherein students are actively engaged in building understanding of facts, ideas, and skills through the completion of instructor directed tasks and activities.

The instructor must prepare a set of guidelines that encourage them to take the lead in designing effective products and then allow them to assume responsibility for their role as creative actors. Students have written a summary of what they want to create. As soon as we have discussed a general question, have students then analyze what they heard that they agree 
with, disagree with, or that gave them a new idea. When students have an idea we must guide them through it with active learning strategies such as these:

- Offer students opportunities to learn actively using virtual prototyping technique

- Give students a general topic and must they define project subject before the formal learning about it begins. They can do research, find examples, predict the main points, or complete other free-flowing activities that expose them in a general way to the material and provide background knowledge in a way that engages students fully. Their research can be online or with materials that we provide

- Have students identify the various characteristics of something under study, classify the main points, or even match up questions and answers by first placing each component of their assignment on a note card according to various criteria

- Give students a list of events to put in order about a scenario

- Ask students to model the right way to do personalizing project. This model can be powerful motivator

- Give students a set of questions that they will answer. Discuss the questions

- Help them see how the questions are aligned with the project and how they should answer them

- Give students a checklist of the key points to watch for so that they can check them off as they find them while working

- Invite students to stretch their imagination by asking them to do something that appears as real: design a virtual structure that is identical to real structure

- Ask students to create virtual prototypes that they believe could possibly have a real homonymous

- Allow students opportunities to independently analyze selections of their own choosing. Independent analyzing is an important way for students to broaden the scope of their background knowledge

\section{Virtual prototyping technology}

An excellent resource to explore the imagination for our students is the active learning by virtual prototyping technique. In recent years, increasing attention has been devoted to virtual learning. Individual characteristics are known to play a crucial role in learning processes but only limited research has been conducted in the context of virtual settings. Therefore, we used an integrated multi method approach in order to examine the impact of types of academic motivation on virtual learning. The domain of investigation is the virtual prototyping. The virtual product development replaces traditional material object test with digitized form product by building product's digital model. Virtual prototype technology is a kind of engineering method which can shorten new product development cycles by replacing cost physical prototype with virtual digital model.

Typical product development cycles can be tedious and expensive procedures, particularly when physical prototypes are required. When a tangible model is involved, the product must be designed, built, tested, and then fixed accordingly. Physical prototypes must be built and re-built after every unsuccessful test, making them a less than optimal choice for a company that values efficiency. With virtual prototyping, however, the development of a product moves straight from design to testing and analysis, and then finally to build. Virtual prototypes allow for the digital exploration of a complete simulated product before it is actually built, decreasing the number of rebuilds necessary and minimizing material waste. Virtual prototyping therefore allows a product to move to market more quickly and efficiently. Virtual prototypes in all forms allow a company to cut down on costs, minimize rebuilds, and move products to market more efficiently. Because of the recent innovations made to virtual technologies, virtual prototypes are more affordable and versatile than ever. Small and medium-sized businesses can now afford to make the move from physical 
prototyping to virtual prototyping, a luxury that was previously only afforded to larger corporations. Any company that desires now has the opportunity to greatly improve their product development cycles through the use of virtual prototyping. The use of the virtual prototyping technique is helpful in areas such as Construction and Engineering.

In this paper the target users of the virtual prototypes models are students, futures civil constructions engineers and automatics engineers. Here, the virtual prototyping technique was applied for educational purposes. We give two examples.

\subsection{Example from civil constructions engineering}

In the first example the virtual prototyping techniques were applied to the development of models related to the construction process.

At present, when carrying out a project, the use of visual programming and, in particular, those relating to $3 \mathrm{D}$ modeling, makes a very positive contribution towards improving the rigorously and correct comportment and, in general to the understanding of spatial configurations in their environment.

Models concerning construction need to be able to generate changes in the project geometry. The integration of geometric representations of a building together with scheduling data related to construction planning information is the basis of $4 \mathrm{D}(3 \mathrm{D}+$ time $)$ models. Thus, in this field, 4D models combine 3D models with the project timeline, and virtual technology has been used to render 4D models more realistic allowing interaction with the environment representing the construction site.

The 4D models are being used to improve the production, analysis, design management and construction information in many phases and areas of construction projects.

The Virtual Building Technique (VBT) has been developing and implementing applications based on this technique providing better communication between the partners in a construction project. Note the contribution of VBT in the example illustrated in Fig. 1 to support conception design, to introduce the plan and to follow the evolution of the intelligent parts of a sportive construction.

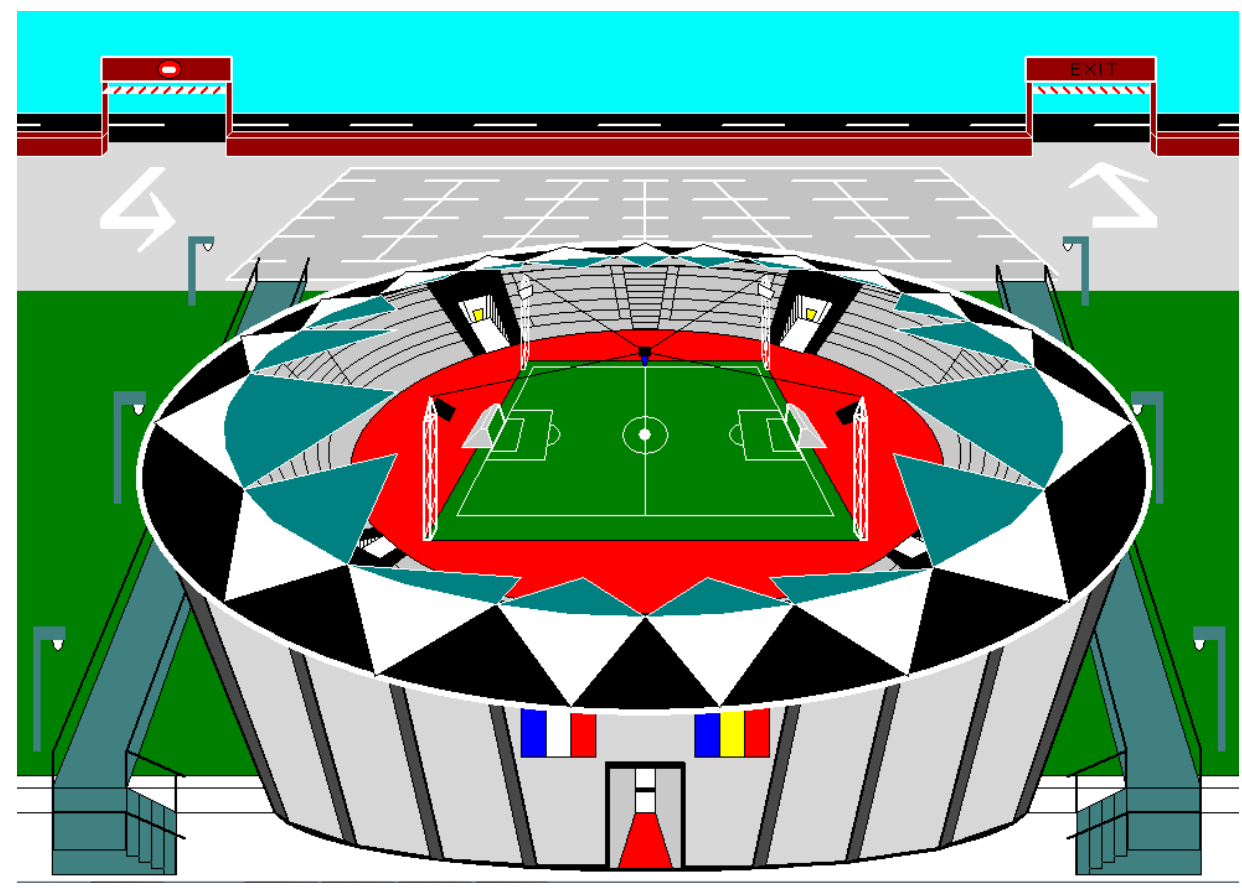

Fig. 1 Virtual intelligent sportive building

The virtual prototype model, created to help the management of intelligent systems in buildings, allows the visual and interactive transmission of information related to the 
behavior of the elements, defined as a function of the time variable. These applications allow the visual simulation of the physical progression of each type of work and also assist in the study of the necessary equipment needed and how it functions on site.

The didactic project model presented in the text shows a sequence of the evolution of the diary activity that implies the evolution of the intelligent parts, allowing step-by-step visualization. The models concern a sportive building and the significant components of an intelligent building, each with different degrees of detail and technical information.

This application clearly demonstrated that the 3D geometric model allowed a quicker understanding of the structural organization of the building and a useful tool for the surveying and mapping of its intelligent parts. The 3D models helped work out many kinds of data and also to identify incompatibilities in the introduction of new elements within intelligent structures.

The virtual prototypes models appear as an important tool for compartmental surveillance of the intelligent structures and for supporting decisions based on the visual analyses of alternative solutions. In this case, many alterative solutions were modeled and finally were worked out the optimal solution.

\subsection{Example from automatics engineering}

Another interesting application of the virtual prototyping technique is the prediction of the robotic tasks. The robot virtual prototype could be to use as an early predictor of possible robot malfunction or hardware problems. This would give an opportunity to change a robot program before it stops working in the middle of a work task.

The virtual prototype is used as a forward model of the controlled robot to predict its behavior in the real world. The predictions are based on a copy of the robot commands acting on the real robot.

These predictions are used as intuitive way to motion control method to programming physical robot through the imitation of the virtual robot prototype. Movement imitation requires a demonstrator: the demonstrator is the virtual robot prototype and the imitator is the physical robotic arm. The dynamics of the motion of the virtual robot is reproduced by the physical robot. The virtual prototype is used in an inner control loop to generate sequences of actions that guide the physical robot towards a target state.

The fast internal loop is functionally equivalent to an inverse-dynamic model that controls a robot without feedback. The virtual prototype as predictor can greatly improve control performance if the virtual model is correct.

In order to react as precisely as possible to a given situation and to calculate the behavior of the robots we need to know their exact positions at every moment (i.e. at every virtual frame). However, due to the system delay, the system can actually react to commands only after some time. When moving faster the delay becomes very important since the error between the real positions of the virtual robot position, used for control, may grow.

The last frame captured from virtual robot reflects a future position of the physical robot, and we need to send commands so that they are consumed by the physical robot in a future frame. Predicting the present position of the robot is therefore not enough: we need to predict its future position, at the time when the new commands will arrive and will be consumed.

These predictions are used as a basis for control. We use real recorded pre-processed data of moving robots to prepare the virtual models and teach the system to predict their positions one frame in advance. In order to correct the immanent error associated with the system's latency we apply virtual prototyping and programming by imitation to process the actions and sent commands to the physical robot during the last frame captured from the virtual prototype.

The concept of robot motion prediction was introduced to clearly understand what the robot must to do when trying to localize visual objects. His suggestion was that the physical robot can predict the situation (position and orientation) using her virtual prototype rather than 
physical sensory signals. Based on virtual model, the physical robot situation is made available before physical sensory signals become available.

Programming problem based on virtual model is to predict the position and the orientation of the robot - a frame forward into the future - and to use these predicted values for the behavior control of the physical robot, rather than the values from the vision directly.

One provide the last virtual robot positions and orientations (relative to the current physical robot position and orientation) and one prepare the commands to supply forward the physical model. The physical robot is trained to predict the position and orientation for a given situation. All physical feedback control loops exhibit a certain delay, depending on the system inertia, on the input and output speed and, of course, on the speed at which the system processes information.

Figure 2 shows a virtual plant equipped with a robot arm. A virtual robot prototype is created using a simulator. The simulator allows quick evaluation of the consequences of actions without interacting with the external world. If there are multiple action options during a work task, the virtual prototype created by simulator could be used to decide which action to take.

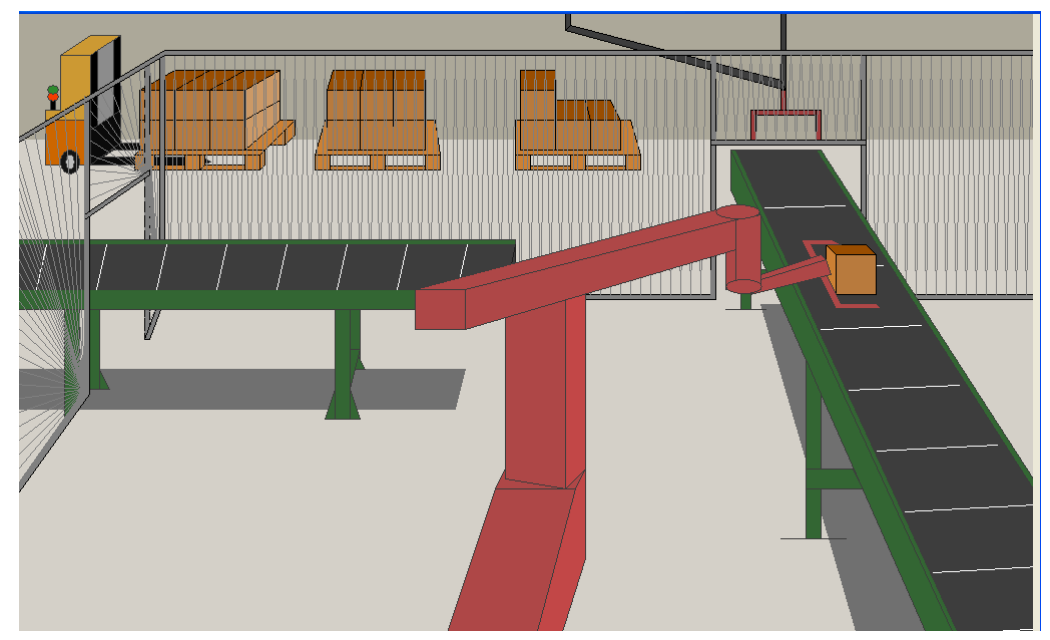

Fig.2. Driving a robot arm to a given target using a virtual prototype arm as predictor

The homonyms physical robot arm drives first to the target position with a given speed, but because of the delay it does not stop right on it; the robot drives further against the floor and then, with low speed, again to the target position for a certain time.

We have successfully developed, implemented and tested virtual models on an experimental platform for predicting the motion of the physical robots.

\section{Conclusion}

There are many possibilities for active learning to create of computational models as virtual prototypes, mainly where the project is suitable for description along its sequential stages of development. The innovative design technologies would need to ensure that the end users achieve the utilization of its abilities in optimization of the projects. The applications with these characteristics make the advantage of using visual programming and virtual prototyping technique as tool of active learning process. They provide a large range of computer subroutines with reference to the scenario of virtual prototype structures and their behavior.

Visual programming technique allows users to explore and manipulate 3D interactive environments in real time. This technique is seen today as an integrating technique, with great potential for communication between project participants, and most recently, as a tool for the support of decision-making. 
Virtual prototypes structures will provide very useful guidance for practicing engineers, researchers, designers, technologists, mathematicians and specialists in computer aided design technique.

This paper purposes and suggests the innovative tools for design in engineering for avoid the limitations of conventional design methods. The authors hope that this paper would be useful for students and attempts to discuss with her many aspects of the active learning based on the virtual prototyping technique.

\section{References}

1. Jim Eison: Using Active Learning Instructional Strategies to Create Excitement and Enhance Learning, Expanded and Updated March 2010 Department of Adult, Career \& Higher Education University of South Florida

2. Isabelle Guyon Gavin Cawley, Gideon Dror, Vincent Lemaire : Results of the Active Learning Challenge, Workshop and Conference Proceedings 16 (2011), pp. 19-45 Workshop on Active Learning and Experimental Design

3. Jacobson, A. R., Militello, R., \& Baveye, P. C., (2009). Development of computerassisted virtual field trips to support multidisciplinary learning. Computers and Education, 52(3), pp. 571-580.

4. Bart Rienties, Dirk Tempelaar, Piet Van Den Bossche, Wim Gijselaers, Mien Segers: Students' motivations and their contributions to virtual learning, In Proceedings of the 8th international conference on International conference for the learning sciences Volume 2, pp. 254-261

5. De Laat, M., Lally, V., Lipponen, L., \& Simons, R.-J. (2007). Online teaching in networked learning communities: A multi-method approach to studying the role of the teacher. Instructional Science, 35(3), 257-286.

6. Cecil, J., Kanchanapiboon, A. (2007) Virtual Engineering Approaches in Product and Process Design. International Journal of Advanced Manufacturing Technologies, No. 31, p. 846-856, DOI 10.1007/s 00170-005-0267-7

7. Guo, H.L., Li, H., Skitmore, M. (2010) Life Cycle Management of Construction Projects Based on Virtual Prototyping Technology. Journal of Management in Engineering, 26(1), p. $41-47$

8. Li, H., Chan, N., Huang, T., Guo, H.L., Lu, W., Skitmore, M. (2009) Optimizing Construction Planning Schedules by Virtual Prototyping Enabled Resource Analysis. Automation in Construction, 18, p. 912-918

9. Park, H., Moon, H.C., Lee, J.Y. (2009) Tangible Augmented Prototyping of Digital Handheld Products. Computers in Industry, 60(2), p. 114-125

10. Pektas, S.T., Ozguc, B. (2011) Virtual Prototyping for Open Building Design. Open House International, Vol. 36, No. 4, p. 46-56

11. Fratu A, Bécar J-P, Robots Collision Avoidance Using Learning through Imitation, ISEEE-2013, 4th International Symposium on Electrical and Electronics Engineering (ISEEE) October 11-13, 2013 Galati, Romania IEEE Catalog Number CFP1393K-USB, ISBN 978-1-4799-2441-7 Xplore Digital Library : http://ieeexplore.ieee. org/xpl/ mostRecentIssue.jsp ?punumber $=6662537$

12. Fratu, A., Fratu, M. (2011) Visual programming in Delphi environment - with Application in Robotics. Second edition, Transilvania University Press, ISBN 978-973-598-963-7 